\title{
Silencing hypoxia-inducible factor-1 $\alpha$ inhibits cell migration and invasion under hypoxic environment in malignant gliomas
}

\author{
SATOSHI FUJIWARA ${ }^{1}$, KOU NAKAGAWA ${ }^{1}$, HIRONOBU HARADA ${ }^{1}$, SHIGEYUKI NAGATO ${ }^{1}$, \\ KOJI FURUKAWA ${ }^{1}$, MIKIO TERAOKA ${ }^{1}$, TOSHIMOTO SENO ${ }^{1}$, KEIZO OKA ${ }^{2}$, \\ SHINJI IWATA ${ }^{1}$ and TAKANORI OHNISHI ${ }^{1}$ \\ ${ }^{1}$ Department of Neurosurgery, Ehime University School of Medicine; \\ ${ }^{2}$ Integrated Center of Sciences, Ehime University, Ehime, Japan
}

Received November 23, 2006; Accepted January 5, 2007

\begin{abstract}
Malignant gliomas are characterized by active invasiveness, necrosis, and vascular proliferation. These pathological features have been speculated to be caused by tissue hypoxia. Hypoxia-inducible factor-1 (HIF-1), which is controlled by rapid stabilization of the HIF- $1 \alpha$ subunit, is a pivotal transcriptional factor in the cellular response to hypoxia. Although many studies have described the relationship between tumor angiogenesis and hypoxic environment, the roles of HIF-1 in cell invasion have been barely elucidated in malignant gliomas. We investigated the role of HIF-1 $\alpha$ in the motile and invasive activities of human glioma cells under hypoxia. Four malignant glioma cell lines, U87MG, U251MG, U373MG, and LN18, were cultured under 21 and $1 \%$ oxygen concentration. Expression of HIF-1 $\alpha$ under hypoxia was observed to be much higher than that under normoxia in all cell lines. Introducing HIF-1 $\alpha$-targeted small interfering RNA (HIF-1 $\alpha$ siRNA) into the glioma cell lines resulted in downregulation of HIF- $1 \alpha$ expression, and significantly suppressed glioma cell migration in vitro. Furthermore, invasiveness was significantly reduced in the cells transfected with HIF-1 $\alpha$ siRNA compared with those transfected with the control siRNA. Co-culture of glioma spheroids and rat brain slices showed that HIF-1 $\alpha$ siRNAtransfected glioma cells failed to invade the surrounding normal brain tissue in an organotypic brain slice model. These effects of HIF-1 $\alpha$ siRNA were more conspicuous under hypoxia than under normoxia. In addition, under hypoxic conditions, the level of matrix metalloproteinase (MMP)-2
\end{abstract}

Correspondence to: Dr Takanori Ohnishi, Department of Neurosurgery, Ehime University School of Medicine, Shitsukawa, Toon, Ehime 791-0295, Japan

E-mail: tohnishi@m.ehime-u.ac.jp

Key words: hypoxia-inducible factor- $1 \alpha$, hypoxia, invasion, siRNA, glioma
mRNA was upregulated, and that of tissue inhibitor of metalloproteinase (TIMP)-2 was downregulated in all glioma cell lines. Treatment with HIF-1 $\alpha$ siRNA resulted in downregulation of MMP-2 mRNA and upregulation of TIMP-2 mRNA. Furthermore, the enzyme activities of MMP-2 and MMP-9, both of which were activated by hypoxia, decreased with the introduction of HIF-1 $\alpha$ siRNA. These findings suggest that overexpression of HIF-1 $\alpha$ induced by hypoxic stress is an essential event in the activation of glioma cell motility through alteration of invasion-related molecules. Targeting the HIF-1 $\alpha$ molecule may be a novel therapeutic strategy for malignant gliomas.

\section{Introduction}

Almost all primary brain tumors of glial cell origin, especially malignant gliomas, are characterized by high invasiveness. This usually prevents complete remission, as infiltrative growth into the surrounding normal brain is responsible for the ineffectiveness of traditional therapeutic modalities such as surgery, radiotherapy, and chemotherapy. To overcome glioma invasion, better understanding of its molecular and cellular mechanisms is required.

It is well known that hypoxia affects tumor cells both genetically and epigenetically, and contributes to tumor heterogeneity and aggressive growth patterns. Like other malignant solid tumors, malignant gliomas proliferate under the hypoxic conditions with reduced supplies of oxygen and nutrients that occur after cell proliferation. Tumor progression under the adverse conditions of hypoxia requires an effective adaptation to the environment. Hypoxia-inducible factor-1 (HIF-1) is a master transcription factor of oxygen-regulated genes and plays an essential role in adaptation to hypoxia $(1,2)$. HIF-1 recognizes a hypoxia response element consensus sequence in the promoter of a broad range of target genes related to various aspects of tumor biology, including cell proliferation, cell survival, angiogenesis, and extracellular matrix (ECM) metabolism. HIF-1 is a heterodimeric, basic, helix-loop-helix protein composed of HIF- $1 \alpha$ and HIF- $1 \beta$ subunits. HIF- $1 \alpha$, which is rapidly degraded in normoxia, becomes stabilized 
and activated under hypoxic conditions and forms complexes with constitutively expressed HIF-1ß (3). Therefore, HIF-1 accumulates under hypoxic stimuli, and HIF- $1 \alpha$ is detected in large amounts in solid tumors containing hypoxic regions. Previous studies have shown that overexpression of HIF-1 $\alpha$ in surgical specimens is positively related to tumor aggressiveness and poor prognosis in human neoplasms (4-7). Significant upregulation of HIF-1 $\alpha$ expression has been demonstrated in high-grade gliomas compared with low-grade gliomas, and is associated with treatment failure and increased mortality $(8,9)$. Recently, the role of HIF-1 $\alpha$ in tumorigenesis has attracted much attention for the development of novel anti-cancer therapies, although most studies have focused on the oncological effects of HIF- $1 \alpha$ on cell growth and angiogenesis. As mentioned above, tumor invasion is an important prognostic factor in patients with glioma. Therefore, elucidation of the relation between HIF-1 $\alpha$ expression and glioma cell invasion would provide useful information for the establishment of HIF-1-targeted therapy for malignant glioma. Moreover, little is known about the influence of HIF-1 $\alpha$ expression induced by hypoxia on glioma cell invasion.

In this study, we investigated whether downregulation of HIF-1 $\alpha$ synthesis alters glioma cell migratory and invasive activities under hypoxic condition using a small interfering RNA for HIF-1 $\alpha$ (HIF- $1 \alpha$ siRNA). To analyze cell motility under normal living conditions, we examined changes in the motile capacity of glioma cells provoked by inhibition of HIF- $1 \alpha$ expression in a brain slice model analogous to normal brain conditions in vivo. To determine the molecular and biochemical mechanisms of the suppressive effects of HIF-1 $\alpha$ siRNA on glioma cell invasion, we examined the expression and enzymatic activities of matrix metalloproteinase (MMP)-2 and -9 and tissue inhibitors of metalloproteinase (TIMP)-2.

\section{Materials and methods}

Cell cultures and hypoxic treatment. Human malignant glioma cell line U87MG was obtained from the American Type Culture Collection (Manassas, VA), U251MG and U373MG were generously provided by Dr N. Arita (Hyogo College of Medicine, Hyogo, Japan), and LN18 was generously donated by Dr M. Tada (Hokkaido University School of Medicine, Sapporo, Japan). All cell lines were maintained in Dulbecco's modified Eagle's medium (DMEM) with $10 \%$ heat-inactivated fetal bovine serum (FBS) and antibiotics (penicillin G, $100 \mathrm{U} /$ $\mathrm{ml}$; and streptomycin, $100 \mu \mathrm{g} / \mathrm{ml}$ ) and incubated at $37^{\circ} \mathrm{C}$ under standard conditions of $100 \%$ humidity, $95 \%$ air and $5 \% \mathrm{CO}_{2}$ (normoxia). For hypoxic treatment, the cells were incubated in an atmosphere of $1 \% \mathrm{O}_{2}, 5 \% \mathrm{CO}_{2}$, and $94 \% \mathrm{~N}_{2}$ under intermittent flushing with nitrogen, then sealed and incubated at $37^{\circ} \mathrm{C}$ for $2,8,16$, and $24 \mathrm{~h}$. To evaluate the gene silencing effect of RNA interference by Western blot analysis, cells were incubated for $2 \mathrm{~h}$ under hypoxic conditions.

Treatment of cells with siRNA. HIF-1 $\alpha$ siRNA was designed by searching the coding sequence of HIF-1 $\alpha$ (GenBank accession no. NM_001530) for two adenines followed by nineteen nucleotides that had a GC content of $\sim 50 \%$ and did not contain more than three thymines or adenines in a row. According to this rule, the target sequence for human HIF-1 $\alpha$ mRNA was localized at a position of 373 bases downstream of the start codon. The forward and reverse RNA strands (CUA ACU GGA CAC AGU GUG U $d t d t$ ) and (ACA CAC UGU GUC CAG UUA G $d t d t$ ) with two deoxythymidine overhangs were synthesized and annealed (Dharmacon Research, Inc.). These sequences were checked for nonhomology to any human gene by BLAST. For transfection, $2 \mu 1$ siLentFect Lipid Reagent (Bio-Rad Laboratories, Hercules, CA) was mixed with $98 \mu \mathrm{l}$ of Opti-MEM (Invitrogen, San Diego, CA, USA), and HIF-1 $\alpha$ siRNA was diluted with Opti-MEM to obtain $200 \mu \mathrm{l}$ of $60 \mathrm{nM}$ solution. These two solutions were combined, gently mixed, and incubated at room temperature for $15 \mathrm{~min}$ to form the transfection mixture. All glioma cell lines $\left(1 \times 10^{5}\right.$ in $2 \mathrm{ml}$ of medium containing serum) were seeded in 6-well plates and incubated for $24 \mathrm{~h}$ before the transfection. Then, DMEM was removed and replaced with $1 \mathrm{ml}$ of the same fresh medium. The transfection mixture was added to all cultures, making a final siRNA concentration of $10 \mathrm{nM}$, and the cells were incubated at $37^{\circ} \mathrm{C}$ for $6 \mathrm{~h}$ under normoxic conditions. The mixture was replaced with fresh medium containing serum, and glioma cells could be assayed from $16 \mathrm{~h}$ thereafter. As a control for HIF- $1 \alpha$ siRNA, we used a corresponding random siRNA sequence (AUU GUA UGC GAU CGC AGA C $d t d t$ ). These sequences were tested for possible homology to other human genes using BLAST.

Western blot analysis. After normoxic or hypoxic treatment, the culture dishes were immediately placed on ice and washed twice with ice-cold PBS and harvested in lysis buffer. Protein concentrations were determined with a BCA protein assay kit (Pierce Biotechnology, Inc. Rockford, IL). Protein (10 $\mu \mathrm{g})$ from each sample was separated by $10 \%$ sodium dodecyl sulfate (SDS)-Tris glycine gel electrophoresis and transferred to a polyvinylidene difluoride membrane (Bio-Rad Laboratories, Hercules, CA). The membranes were blocked with $1 \%$ dry milk and $0.1 \%$ Tween-20 in Tris-buffered saline and incubated with primary antibodies, mouse anti-human HIF-1 $\alpha$ monoclonal antibody (Transduction Laboratories), and human antiB-actin monoclonal antibody (Sigma-Aldrich Fine Chemical, St. Louis, MO), followed by horseradish peroxidase-conjugated sheep anti-mouse IgG antibody (Amersham, Piscataway, NJ). The membranes were developed according to the Amersham enhanced chemiluminescence protocol.

Cell viability assay. To assess the effect of hypoxic conditions and siRNA transfection on glioma cell viability, an MTT assay was performed according to the method of Mosmann (10). In brief, $3 \times 10^{3}$ cells (U87MG, U251MG, U373MG, and LN18) were seeded in each well of 96-well flat-bottom plates. For the effect of hypoxia, the culture dishes were incubated at the same time under the normoxia and hypoxia. For the effect of siRNA transfection, $24 \mathrm{~h}$ after incubation, HIF-1 $\alpha$ siRNA and control siRNA were transfected as described. At $72 \mathrm{~h}$ after incubation under 21 and $1 \%$ oxygen concentration, $10 \mu 1$ MTT $(5 \mathrm{mg} / \mathrm{ml})$ was added, and the plates were incubated for an additional $3 \mathrm{~h}$. The culture medium was removed, the formazan crystals were dissolved in $100 \mu 1$ isopropanol with $0.04 \mathrm{~N}$ $\mathrm{HCl}$, and the absorbance was read on a microplate reader (SpectraAmax, Molecular Device Corp.) with a test wavelength of $540 \mathrm{~nm}$ and a reference wavelength of $620 \mathrm{~nm}$. 
In vitro migration assay. The migratory responses of glioma cells to their own conditioned medium were assessed using the modified Boyden chamber method with 48-well microchemotaxis chambers (Nucleopore, Pleasanton, CA) as previously described $(11,12)$. In brief, glioma cells transfected with HIF-1 $\alpha$ siRNA or control siRNA were harvested and resuspended in DMEM containing $0.1 \%$ BSA at a density of $8 \times 10^{5}$ cells $/ \mathrm{ml}$. Cell suspensions $(30 \mu \mathrm{l})$ were placed in the upper well of the chamber and serum-free conditioned medium was placed in the lower well as a chemoattractant. The filter was a polyvinylpyrolidone-free polycarbonate membrane with $8.0-\mu \mathrm{m}$ pores. The chamber was incubated for $6 \mathrm{~h}$ at $37^{\circ} \mathrm{C}$ under normoxic or hypoxic conditions at the same time, and cells that had migrated to the lower surface of the filter were fixed and stained with Diff-Quik (Scientific Products, Harleco, Gibbstown, NJ). Cells were counted in three independent fields $\left(0.25 \mathrm{~mm}^{2} /\right.$ well $)$.

In vitro invasion assay. The invasive activity of glioma cells was assayed in vitro using Falcon cell culture inserts (Becton Dickinson Biosciences, USA) and a reconstituted basement membrane, Matrigel (Becton Dickinson Biosciences), as previously described (13-16). Briefly, glioma cells treated with HIF- $1 \alpha$ siRNA or control siRNA in DMEM containing $0.1 \%$ BSA were seeded onto the upper sides of insert filters coated with Matrigel ( $60 \mu \mathrm{g} /$ insert) at a density of $1 \times 10^{5}$ cells/ insert. The lower compartment of the Falcon 24-well plates contained $500 \mu 1$ of conditioned medium as a chemoattractant. Two days after simultaneous incubation at $37^{\circ} \mathrm{C}$ under normoxic or hypoxic conditions, the lower surfaces of the culture inserts were fixed and stained with Diff-Quik. In vitro cell invasive activities were quantified as described for the migration assays.

Invasion assay in brain slice model. All animal experiments were conducted in accordance with the guidelines of the Ehime University Committee for Ethics of Animal Experimentation. To assess the effect of HIF- $1 \alpha$ suppression on cell motility under more physiological conditions, we used rat brain slice cultures that mimic in vivo central nervous system conditions. A slice culture of rat whole cerebrum was produced by modifying a previously described organotypic culture method (17-19). Brain slices were prepared from 2-day-old neonatal Wister rats (male; SLC Inc., Japan). After brief anesthesia with diethyl ether, the rats were plunged into a $10 \%$ povidoneiodine solution, and were decapitated using scissors. The whole brains were quickly removed and placed in Hanks' balanced salt solution (HBSS; Life Technologies, Inc., Rockville, MD). The brains were mounted on the stage of a microslicer (Dosaka EM Co. Ltd., Kyoto, Japan) and cut into 500- $\mu$ m coronal slices, which were transferred onto $30-\mu \mathrm{m}$ Millicell-CM inserts with $0.4-\mu \mathrm{m}$ pores (Millipore) in 6-well culture plates. The wells contained $1.0 \mathrm{ml}$ of $50 \%$ Eagle's minimal essential medium with HEPES, $25 \%$ HBSS, 25\% heat-inactivated horse-serum (Life Technologies Inc.), $6.5 \mathrm{mg} / \mathrm{ml}$ glucose, 100 units $/ \mathrm{ml}$ penicillin, $100 \mu \mathrm{g} / \mathrm{ml}$ streptomycin, and $2.5 \mu \mathrm{g} / \mathrm{ml}$ amphotericin B (Fungizone). Brain slices were incubated at $37^{\circ} \mathrm{C}$ in a humidified atmosphere of $95 \%$ air and $5 \% \mathrm{CO}_{2}$. The culture medium was replaced with fresh medium twice per week before the experiment.
Glioma cell spheroid implantation. All human glioma cells transfected with HIF- $1 \alpha$ siRNA and control siRNA were fluorescently labeled with PKH26 (rhodamine) using a kit (Zynaxis Cell Science, Inc., Malvern, PA) as described previously (20). Briefly, $1.0 \times 10^{7}$ harvested glioma cells in serum-free DMEM were resuspended in $1 \mathrm{ml}$ of diluent $\mathrm{C}$, and then PKH26 dye in $1 \mathrm{ml}$ of diluent $\mathrm{C}\left(2 \times 10^{-6} \mathrm{M}\right)$ was added. After incubation of the cells at room temperature for $5 \mathrm{~min}$, the labeling reaction was stopped by adding $2 \mathrm{ml}$ of FBS. The cells were then thoroughly washed to remove free PKH26, and resuspended in DMEM containing 10\% FBS. The labeled glioma cells $\left(5 \times 10^{5}\right)$ were seeded into non-treated $60-\mathrm{mm}$ culture dishes, and incubated under continuous agitation at a speed of $30 \mathrm{rpm}$ on a reciprocating shaker (Taitec, Saitama, Japan) at $37^{\circ} \mathrm{C}$ in a humidified atmosphere of $95 \%$ air and $5 \% \mathrm{CO}_{2}$ for 1 day. The glioma cell spheroids obtained by this method were of $300-400 \mu \mathrm{m}$ in diameter. One rhodaminelabeled glioma cell spheroid was pipetted, placed on a brain slice as close to the corpus callosum as possible, and co-cultured at $37^{\circ} \mathrm{C}$ under normoxic or hypoxic conditions for 3 days. Cell invasion was observed by fluorescence microscopy on days 0 and 3.

Expression of MMP-2 and TIMP-2. After $24 \mathrm{~h}$ of normoxic or hypoxic treatment, total RNA extracted from four human malignant glioma cell lines transfected with HIF-1 $\alpha$ siRNA, control siRNA, and non-treated controls (mocks) using acid guanidinium isothiocyanate phenol chloroform, were used as templates for cDNA synthesis (21). Each RT-PCR reaction consisted of 30 cycles at $94^{\circ} \mathrm{C}$ for $30 \mathrm{sec}, 53^{\circ} \mathrm{C}$ for $30 \mathrm{sec}$, and $68^{\circ} \mathrm{C}$ for $1 \mathrm{~min}$, followed by incubation at $72^{\circ} \mathrm{C}$ for $5 \mathrm{~min}$. The products were electrophoresed on $1.5 \%$ agarose gels including $0.1 \mu \mathrm{g} / \mathrm{ml}$ ethidium bromide. PCR was performed with human HIF-1 $\alpha$, MMP-2, TIMP-2, and glyceraldehyde-3-phosphate dehydrogenase (GAPDH; internal standard)-specific primers. The primers (Hokkaido Biosystems, Sapporo, Japan) used were: 5'-CCCCAGATTCAGGATCAGACA-3' and 5'-CCA TCATGTTCCATTTTTCGC-3' for HIF-1 $\alpha, 5^{\prime}$-CTCTCCT GACATTGACCTTGGCAC-3' and 5'- AAAAAGCTTAC TCGCTGGACATCAGGG-3' for MMP-2, 5'-CTCGGCAG TGTGTGGGGTC-3' and 5'-CGAGAAACTCCTGCTTGG GG-3' for TIMP-2, and 5'-CAAAGTTGTCATGGATGAC C-3' and 5'-CCATGGAGAAGGCTGGGG-3' for GAPDH.

Gelatin zymography. To quantify MMP-2 and MMP-9 activities, gelatin zymography (22) was performed by analyzing the conditioned media of glioma cells transfected with HIF-1 $\alpha$ siRNA and of the controls (mock and control siRNA) using $10 \%$ SDS-PAGE containing $1 \mathrm{mg} / \mathrm{ml}$ of gelatin (Sigma, USA). Cells $\left(5 \times 10^{5}\right)$ were placed in $5 \mathrm{ml}$ of serum-free DMEM and incubated for $24 \mathrm{~h}$ under 21 and $1 \%$ oxygen. The supernatants were mixed with the solution buffer $(2 \% \mathrm{w} / \mathrm{v}$ SDS, $10 \%$ glycerol, $50 \mathrm{mmol} / \mathrm{l}$ Tris- $\mathrm{HCl}, \mathrm{pH} 7.5$, and $0.005 \%$ bromophenol blue) and then $25 \mu \mathrm{g}$ aliquots of this mixture were loaded onto the gel. After electrophoresis, the gels were washed for $1.5 \mathrm{~h}$ at room temperature in washing buffer $(50 \mathrm{mM}$ Tris- $\mathrm{HCl}$, pH 7.5, containing $0.1 \mathrm{mM} \mathrm{NaCl}$ and $2.5 \%$ Triton $\mathrm{X}-100)$ to remove SDS, transferred to a buffer $(50 \mathrm{mM}$ Tris$\mathrm{HCl}, \mathrm{pH} 7.5$, containing $10 \mathrm{mM} \mathrm{CaCl}_{2}$ ), and incubated for $18 \mathrm{~h}$ at $37^{\circ} \mathrm{C}$. The gels were then stained with $0.1 \%$ Coomassie 

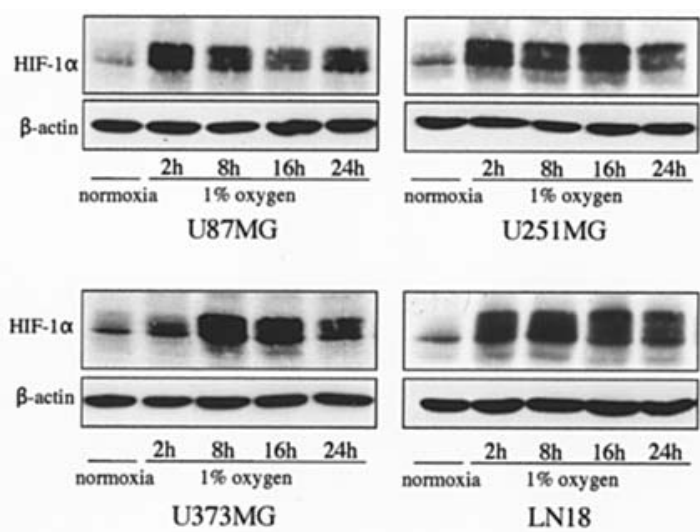

Figure 1. Expression of HIF-1 $\alpha$ protein in human glioma cell lines U87MG, U251MG, U373MG, and LN18. After hypoxic treatment for $0 \mathrm{~h}$ (normoxia), $2,8,16$, and $24 \mathrm{~h}$, cellular extracts from each lysate were subjected to Western blot analysis. HIF- $1 \alpha$ protein expression was detected with a monoclonal antibody against HIF-1 $\alpha$. Top panels show HIF- $1 \alpha$ protein $(120 \mathrm{kDa})$, while $\beta$-actin is shown as an internal control in the bottom panels. Overexpression of HIF-1 $\alpha$ protein was observed by $2 \mathrm{~h}$ of hypoxic treatment in all cell lines. HIF-1 $\alpha$ expression was clearly augmented by hypoxic treatment in all cell lines.

brilliant blue R-250 diluted in $45 \%$ ethanol and $10 \%$ acetic acid, and destained in $20 \%$ ethanol and $5 \%$ acetic acid until clear proteolytic bands were obtained on a homogeneous blue background.

Statistical analysis. The results are representative of experiments repeated at least 3 times and the values are expressed as the means \pm standard deviation (SD). Statistical comparisons between groups were performed using Student's t-test (Stat View, SAS Institute Inc., NC). p-values $<0.05$ were considered statistically significant.

\section{Results}

Effects of HIF-1a siRNA on HIF-1a expression under hypoxia in glioma cells. To assess the change of HIF-1 $\alpha$ synthesis under hypoxic conditions in glioma cells, amounts of HIF-1 $\alpha$ protein in nuclear extracts were assayed by Western blot analysis after $2,8,16$, and $24 \mathrm{~h}$ of hypoxic treatment. In this study, a concentration of $1 \% \mathrm{O}_{2}$ was used to induce hypoxia. Weak HIF-1 $\alpha$ expressions was detected under normoxia in all cell lines. After hypoxic treatment, HIF-1 $\alpha$ proteins were markedly overexpressed at each processing time, compared with those under normoxic conditions (Fig. 1). Next, we examined the effects of HIF- $1 \alpha$ siRNA on HIF- $1 \alpha$ protein expression. Transfection with HIF-1 $\alpha$ siRNA markedly inhibited the overexpression of HIF- $1 \alpha$ after $2 \mathrm{~h}$ hypoxic treatment compared with that of control siRNA and mocks in all glioma cell lines (Fig. 2A). To examine the duration of inhibition of HIF-1 $\alpha$ synthesis by HIF-1 $\alpha$ siRNA, glioma cells were transfected with HIF- $1 \alpha$ siRNA and cultured for 48 h, 96 h, and 7 days under hypoxic conditions. Although clear bands indicating HIF-1 $\alpha$ were not seen until $96 \mathrm{~h}$ of incubation, HIF-1 $\alpha$ proteins was apparently expressed at 7 days (Fig. 2B). Moreover, we examined the influence of siRNA on cell viability and cell growth. After a $96 \mathrm{~h}$ incubation under normoxia and hypoxia,
A
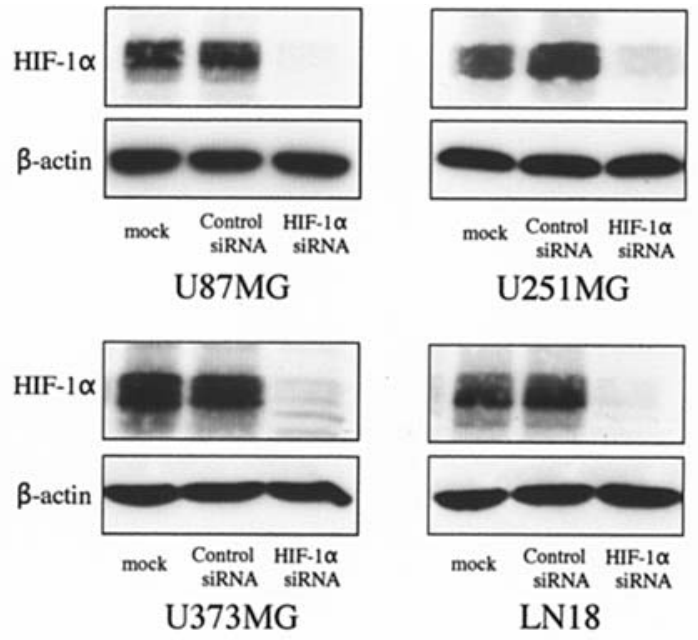

B

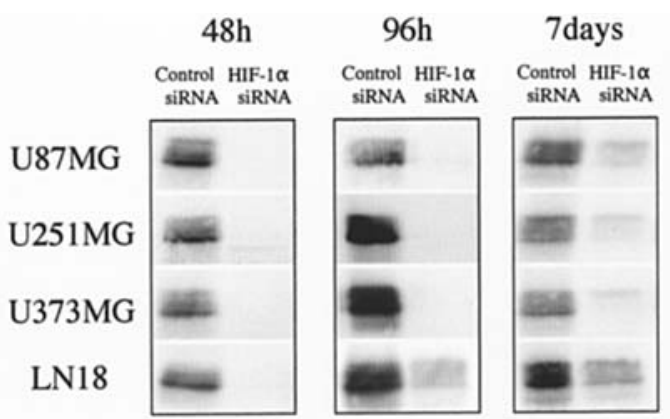

Figure 2. Effects of HIF-1 $\alpha$ siRNA on HIF-1 $\alpha$ protein expression were examined by Western blot analysis. (A) HIF-1 $\alpha$ protein expression after $2 \mathrm{~h}$ of hypoxic treatment in non-treated cells (mocks), cells treated with control siRNA, and cells treated with HIF- $1 \alpha$ siRNA are shown. Transfection with HIF- $1 \alpha$ siRNA repressed HIF- $1 \alpha$ protein synthesis in all glioma cell lines. (B) Effects of HIF- $1 \alpha$ siRNA on HIF- $1 \alpha$ expression at 48 h, 96 h, and 7 days after transfection in cells treated with control siRNA and cells treated with HIF- $1 \alpha$ siRNA. The HIF- $1 \alpha$ band was not clearly seen until $48 \mathrm{~h}$ after transfection, whereas HIF-1 $\alpha$ protein was detected at day 7 in all cell lines.

cell viability, as assessed by the MTT assay, did not differ between cells treated with HIF-1 $\alpha$ siRNA and those with control siRNA compared with that without treatment (Fig. 3). Cell growth suppression was not seen in HIF-1 $\alpha$ siRNA and control siRNA cells (data not shown). Therefore, we performed all subsequent experiments within $96 \mathrm{~h}$ after transfection with siRNA.

Downregulation of HIF-1a expression inhibits glioma cell migration and invasion in vitro. To evaluate the relation between cell migratory ability and HIF- $1 \alpha$ expression under hypoxic conditions, we performed a migration assay using a modified Boyden chamber method under conditions of normoxia and hypoxia. HIF- $1 \alpha$ siRNA-transfected cells showed a tendency to suppressed migratory activity under normoxia; however, there was no significant difference compared with the effect of control siRNA. Under hypoxic conditions, migration of glioma cells transfected with HIF- $1 \alpha$ siRNA was significantly reduced compared with the mocks and control siRNA-transfected cells in all cell lines (Fig. 4).

We investigated the influence of HIF- $1 \alpha$ protein under hypoxia on the glioma cell invasive activity using an in vitro invasion assay. The microphotographs in Fig. 5A show 

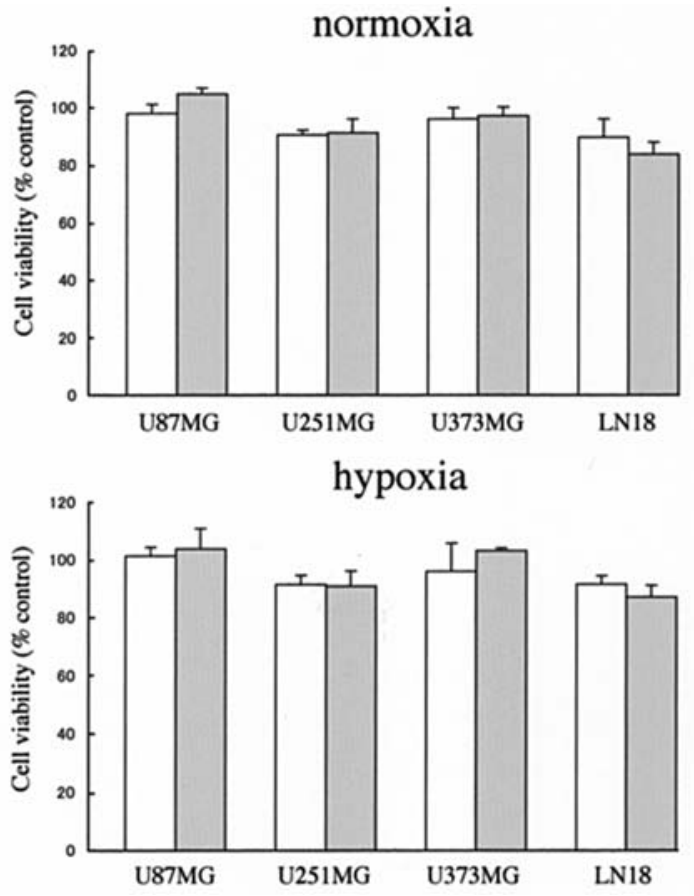

Figure 3. Cell viability after introduction of siRNA was assessed by MTT assay. The glioma cells were seeded at $3 \times 10^{3}$ cells/well in 96-well flatbottom plates. At the indicated times, the absorbance was read on a microplate reader at the dual wavelengths of 540 and $620 \mathrm{~nm}$. The cells were incubated for $72 \mathrm{~h}$ under the normoxia and hypoxia after siRNA transfection. Cell growth and viability did not differ between treatment with HIF-1 $\alpha$ siRNA (gray) and control siRNA (white). Values represent the means \pm SD of four experiments.
U373MG cells invading through the matrigel after $48 \mathrm{~h}$ of incubation with or without siRNA treatment under the conditions of normoxia and hypoxia. Except for the U87MG cells, there were no differences in invasiveness between HIF- $1 \alpha$ siRNA-treated cells and control siRNA-treated cells under normoxia. In contrast, under hypoxic conditions, the invasiveness of glioma cells transfected with HIF-1 $\alpha$ siRNA was significantly suppressed compared with that of the cells treated with control siRNA (Fig. 5B).

Suppression of HIF-1a expression inhibits glioma cell invasion in an organotypic brain slice model. To evaluate the effects of HIF- $1 \alpha$ siRNA on cell motility under more physiological conditions, we investigated the distance migrated by the glioma cells treated with HIF-1 $\alpha$ siRNA and control siRNA on organotypic rat brain slices under normoxic or hypoxic conditions. The brain slice model enabled us to observe the invasion of glioma cells into surrounding brain tissue in conditions analogous to those of normal brain in situ. We implanted rhodamine-labeled spheroids of each glioma cell line into the corpus callosum of the cerebral hemisphere (23). Under normoxic conditions, glioma cells transfected with HIF- $1 \alpha$ siRNA and control siRNA migrated diffusely around the spheroids. Under hypoxia, glioma cells transfected with HIF-1 $\alpha$ siRNA showed repressed migration and invasion of the surrounding normal brain tissues compared with those transfected with control siRNA in all cell lines (Fig. 6A and B).

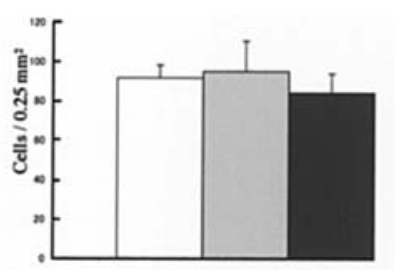

U87MG

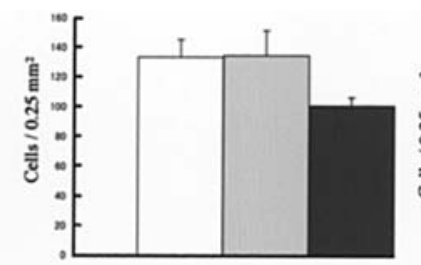

U251MG

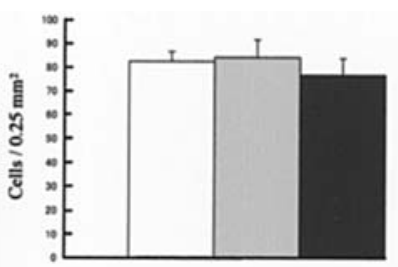

U373MG

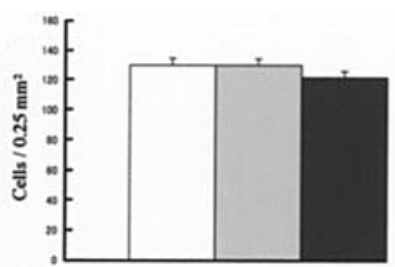

LN18

\section{normoxia}
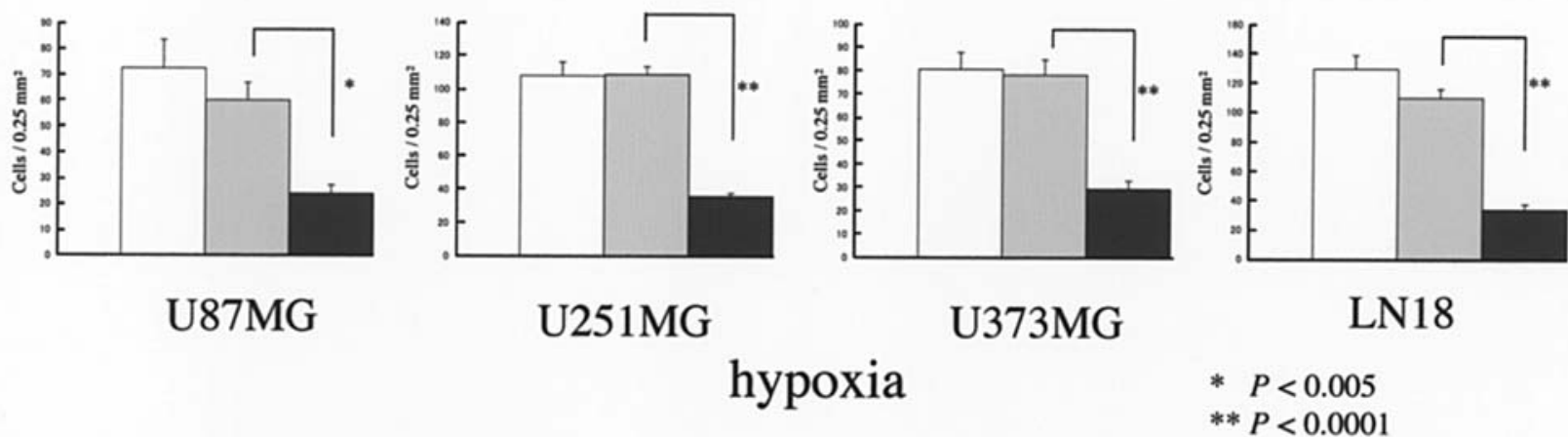

Figure 4. Effects of HIF-1 $\alpha$ siRNA on migration activity of glioma cells. Migration activity was evaluated by a modified Boyden chamber assay method. Non-treated cells (mocks), cells treated with control siRNA, and cells treated with HIF-1 $\alpha$ siRNA were placed in the upper well and the conditioned medium of each group of cells served as a chemoattractant in the lower well. Cells that migrated to the lower surface of the membrane, which had 8- $\mu$ m pores, were stained with Diff-Quik and counted. Migration of glioma cells transfected with HIF-1 $\alpha$ siRNA (black) was significantly reduced compared with that of nontreated cells (white) and control siRNA-transfected cells (gray) under hypoxic conditions. Under normoxic conditions, introduction of HIF-1 $\alpha$ siRNA did not altered the migratory ability of any of the cell lines. Upper panel, normoxia; lower panel, hypoxia. Values represent the mean \pm SD of three experiments. ${ }^{*} \mathrm{p}<0.005,{ }^{* *} \mathrm{p}<0.0001$. 
A

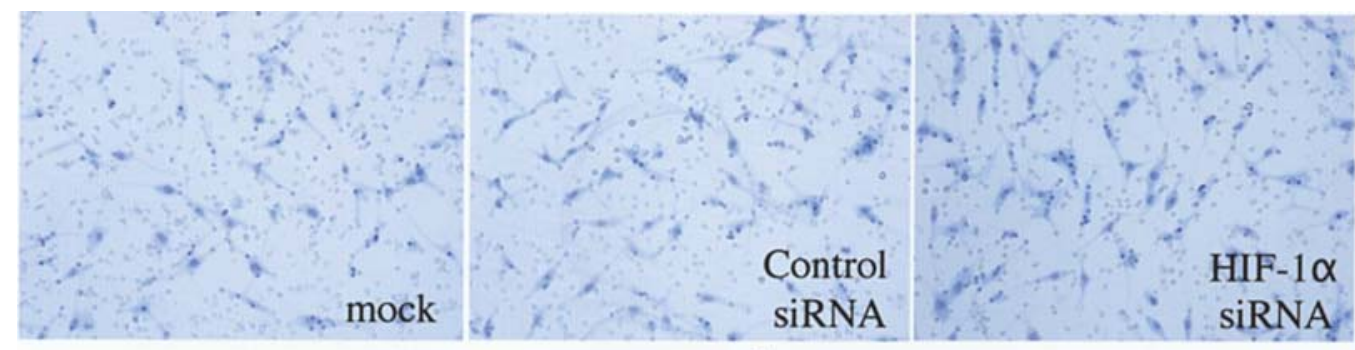

normoxia

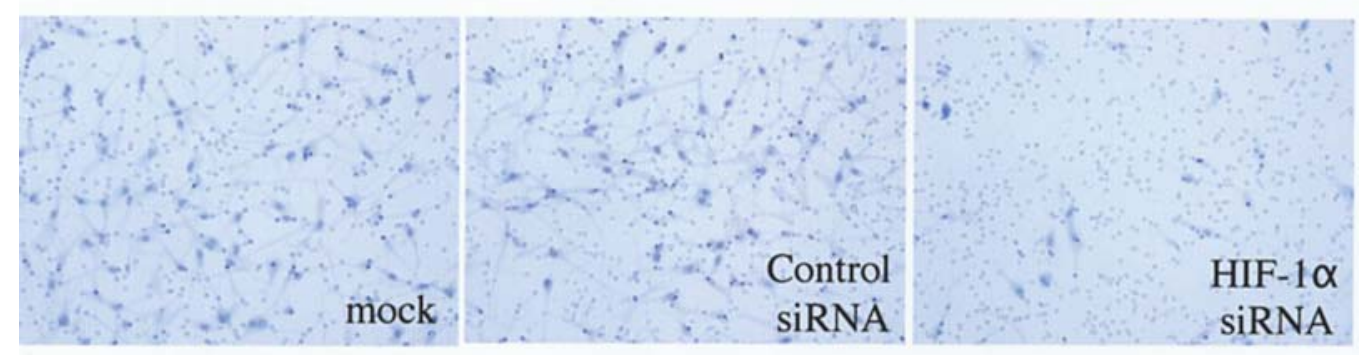

hypoxia

B

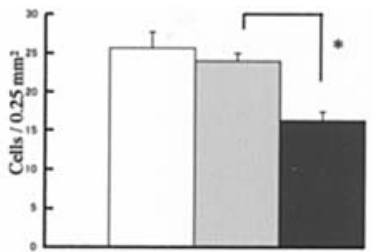

U87MG

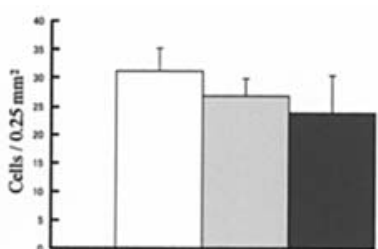

U251MG

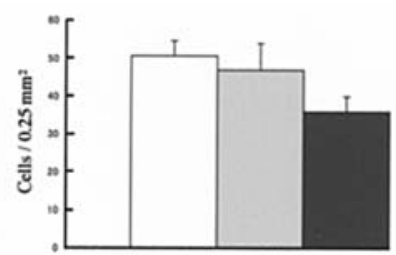

U373MG

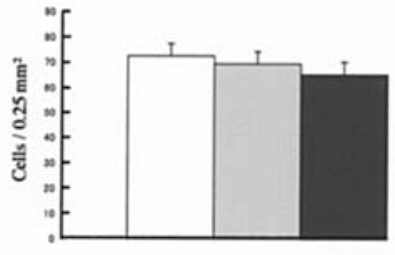

LN18

\section{normoxia}

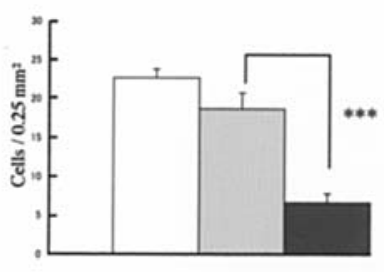

U87MG

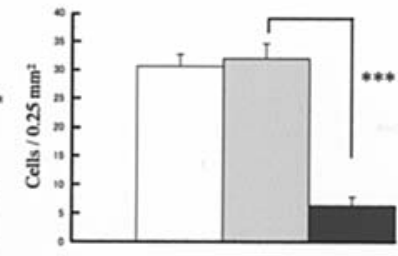

U251MG

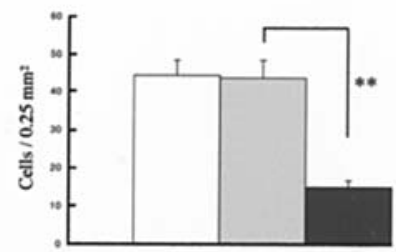

U373MG

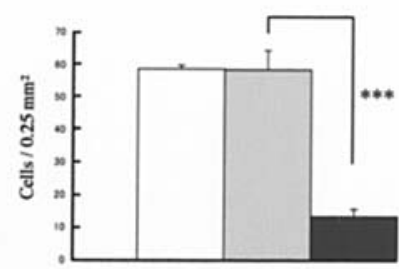

LN18

hypoxia

Figure 5. Effects of HIF-1 $\alpha$ siRNA on glioma cell invasion in vitro. (A) Microphotographs show that, after 48 h of incubation, U373MG glioma cells had invaded the Matrigel to the lower side of an insert filter with $8-\mu \mathrm{m}$ pores. Conditioned medium from glioma cells transfected with siRNA served as a chemoattractant in the lower wells of Falcon 24-well plates. Original magnification, x200. Upper panel, normoxia; lower panel, hypoxia; left, nontreated (mocks); middle, control siRNA; and right, HIF-1 $\alpha$ siRNA. (B) The number of invading cells was counted after 2 days of incubation. The invasiveness of glioma cells transfected with HIF-1 $\alpha$ siRNA (black) was significantly suppressed compared with cells treated with control siRNA (gray). Under normoxic conditions, only U87MG glioma cells treated with HIF-1 $\alpha$ siRNA showed less invasiveness than the cells treated with control siRNA. Values represent the mean \pm SD of three experiments. ${ }^{*} \mathrm{p}<0.005,{ }^{* *} \mathrm{p}<0.001,{ }^{* * *} \mathrm{p}<0.0005$.

Reduction in HIF-1a synthesis decreases MMP-2 expression but increases TIMP-2 expression. We investigated whether expression of MMP-2, TIMP-2, and MMP-9 was affected by hypoxia and HIF- $1 \alpha$ siRNA treatment. MMP-2 mRNA, which was constitutively expressed, was apparently upregulated under the hypoxic conditions in all cell lines. However, MMP-2 mRNA levels were significantly lower in cells treated with HIF-1 $\alpha$ siRNA compared with those treated with control siRNA. Although TIMP-2 mRNA levels were downregulated under hypoxia in all glioma cell lines, introduction of HIF-1 $\alpha$ 
A
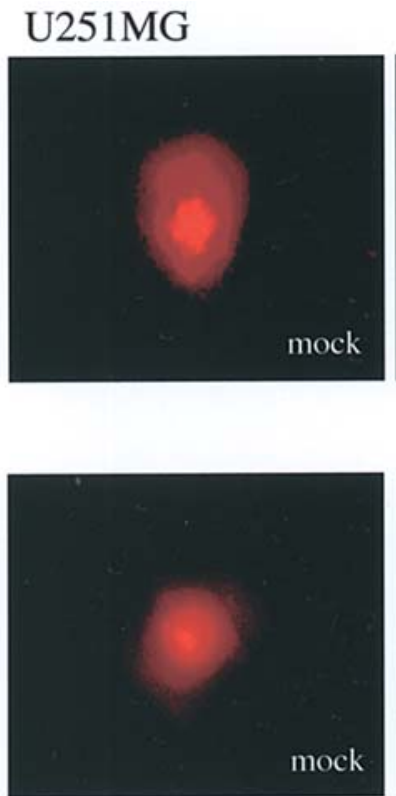

B

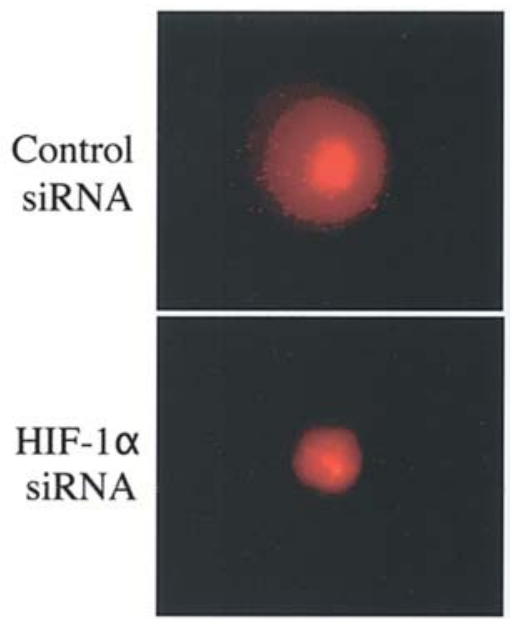

U87MG

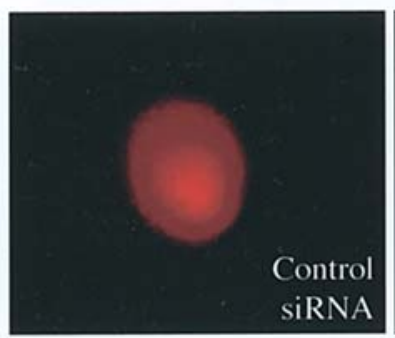

hypoxia
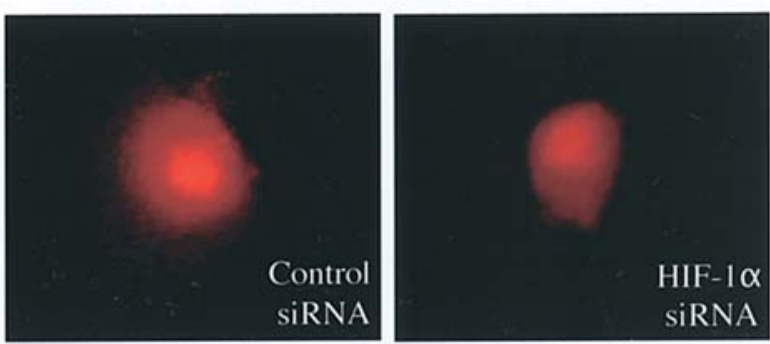

normoxia
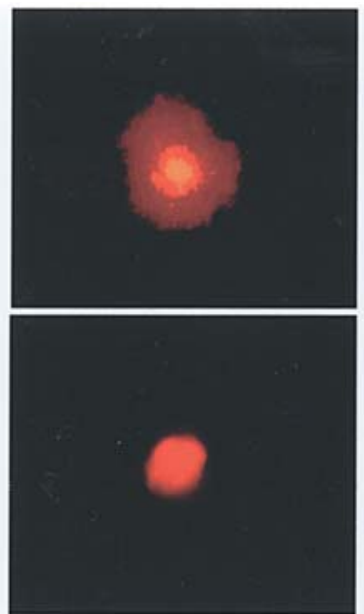

U373MG
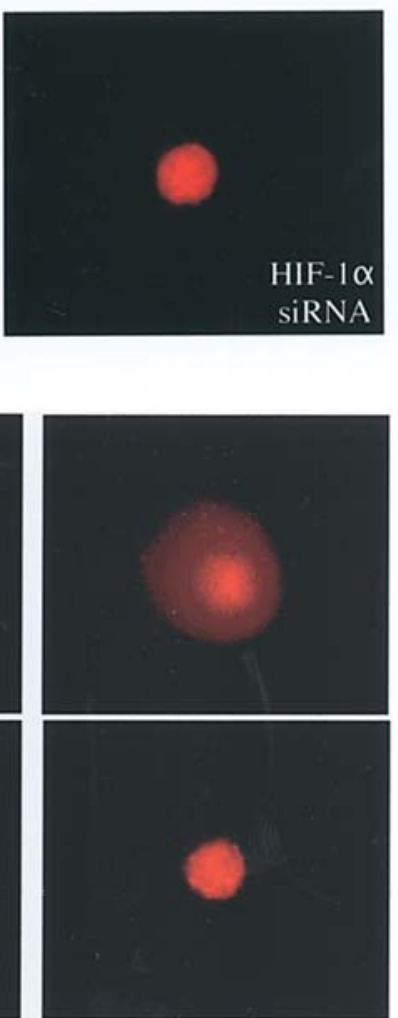

LN18

Figure 6. Invasive behavior of glioma cells transfected with HIF-1 $\alpha$ siRNA on rat brain slices. Rhodamine-labeled glioma cell spheroids were co-cultured with rat brain slices. (A) Fluorescence microphotographs show U251MG glioma cell invasion around the original glioma spheroids under normoxic conditions (upper panel) and hypoxic conditions (lower panel). U251MG glioma cells transfected with HIF-1 $\alpha$ siRNA showed much less invasion of the surrounding normal brain tissues compared with those transfected with control siRNA under hypoxic conditions. There was no difference in the spread of tumor cells between nontreated cells, cells treated with control siRNA, and cells treated with HIF-1 $\alpha$ siRNA under normoxic conditions. Left, nontreated (mocks); middle, control siRNA; and right, HIF-1 $\alpha$ siRNA. (B) Fuluorescence microphotographs show invasion of U87MG, U373MG, and LN18 glioma cells treated with control siRNA (upper panel) and HIF-1 $\alpha$ siRNA (lower panel) under hypoxic conditions. Glioma cells treated with control siRNA actively migrated around the tumor spheroids, whereas the migration of cells treated with HIF-1 $\alpha$ siRNA was inhibited. Original magnification, $x 40$.

siRNA elevated them (Fig. 7A and B). MMP-9 mRNA levels were not affected by hypoxia or HIF-1 $\alpha$ siRNA transfection (data not shown).

Effect of HIF-1 $\alpha$ siRNA on enzymatic activities of MMP-2 and $M M P-9$ under hypoxia. We examined the enzymatic activities of MMP-2 and MMP-9 in the conditioned medium from each cell line using gelatinolytic zymography. MMP-2 and MMP-9 were revealed as 72 and $92 \mathrm{kDa}$ lytic bands, respectively. Both bands were observed in non-treated cells under normoxic conditions, and these bands were more prominent under hypoxic conditions. These results indicate that MMP-2 and MMP-9 were activated under low-oxygen conditions. The intensities of these gelatinolytic bands were clearly decreased in the conditioned medium from HIF- $1 \alpha$ siRNA-transfected cells. This indicates that downregulation of HIF-1 $\alpha$ expression reduced the enzyme activities of MMP-2 and MMP-9, especially under hypoxic conditions in glioma cells (Fig. 8).

\section{Discussion}

In the present study, we showed that HIF-1 $\alpha$ is an important regulator of glioma cell motility under hypoxia. Hypoxia selects for more aggressive and metastatic phenotypes that are associated with poor prognosis (24). Since HIF-1 $\alpha$ is induced by a hypoxic stimulus, it is inevitable that HIF- $1 \alpha$ 
A
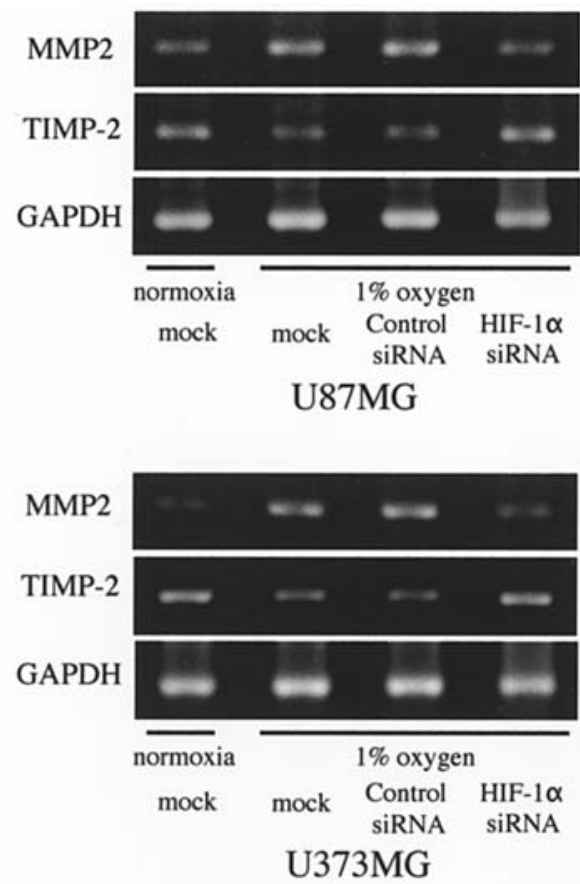

B
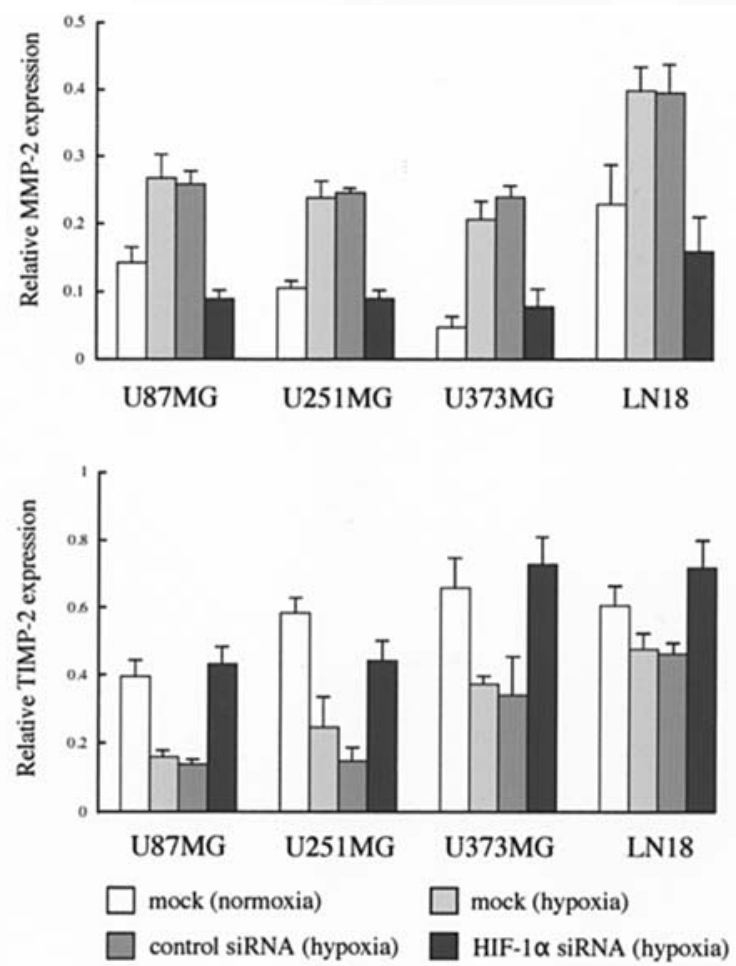

protein is highly expressed in malignant solid tumors containing hypoxic regions. Intense diffuse expression of HIF- $1 \alpha$ protein has been observed in tumor tissues, especially areas of necrosis surrounding malignant gliomas $(8,9)$. Malignant gliomas are characterized by their extremely invasive behavior, leading to the hypothesis that HIF-1 may play a crucial role in glioma cell motility. Therefore, we investigated whether silencing HIF-1 $\alpha$ by HIF- $1 \alpha$-specific siRNA inhibited the migration and invasion of human glioma cells. Recent approaches to the inhibition of targeted molecules include transcription factor decoy, antisense, oligonucleotide and dominant negative mutants, and RNA interference. We used siRNA to downregulate HIF-1 $\alpha$ expression, because
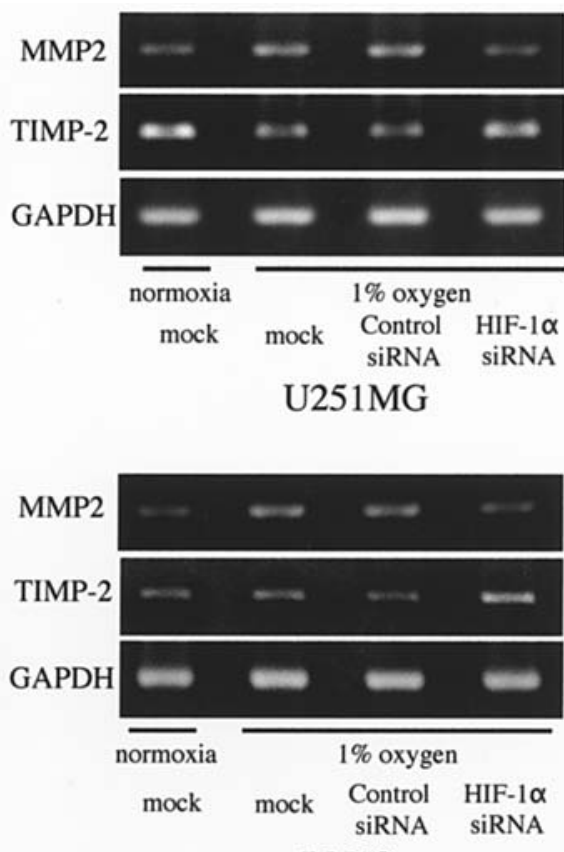

LN18

Figure 7. Expression of MMP-2 and TIMP-2 mRNAs in U87MG, U251MG, U373MG, and LN18 glioma cells incubated under normoxic or hypoxic conditions for $24 \mathrm{~h}$. (A) Total mRNA extracted from glioma cells was amplified by RT-PCR. The PCR products were resolved by electrophoresis on $1.5 \%$ agarose gels and visualized by ethidium bromide staining. GAPDH was used as an internal control. (B) Columns represent densitometric quantification of MMP-2 and TIMP-2 mRNA bands from each glioma cell. Ratios of MMP-2 and TIMP-2 to GAPDH are presented as the mean \pm SD of three independent experiments. MMP-2 mRNA expression was upregulated under hypoxic conditions. In cells treated with HIF-1 $\alpha$ siRNA, MMP-2 mRNA levels were low compared with those treated with control siRNA. In contrast, TIMP-2 mRNA expression was downregulated under hypoxic conditions, but upregulated by suppression of HIF-1 $\alpha$ expression.

siRNA methods can almost abrogate expression of RNA and protein, and enable the consequences to be observed in various tumor cell lines.

In the glioma cell lines used in this study, HIF- $1 \alpha$ protein levels were low under normoxic conditions, but were highly upregulated by hypoxic treatment. Transfection with HIF-1 $\alpha$ siRNA inhibited HIF-1 $\alpha$ protein expression. However, neither HIF-1 $\alpha$ siRNA nor control siRNA affected cell growth or cell viability under normoxic or hypoxic conditions. Some studies have shown that treatment with HIF-1 $\alpha$ siRNA under normoxia and hypoxia suppressed constitutive HIF-1 $\alpha$ as well as hypoxiainduced HIF-1 $\alpha$, attenuated cell proliferation, and induced apoptosis (25). The significance of HIF-1 $1 \alpha$ expression remains 


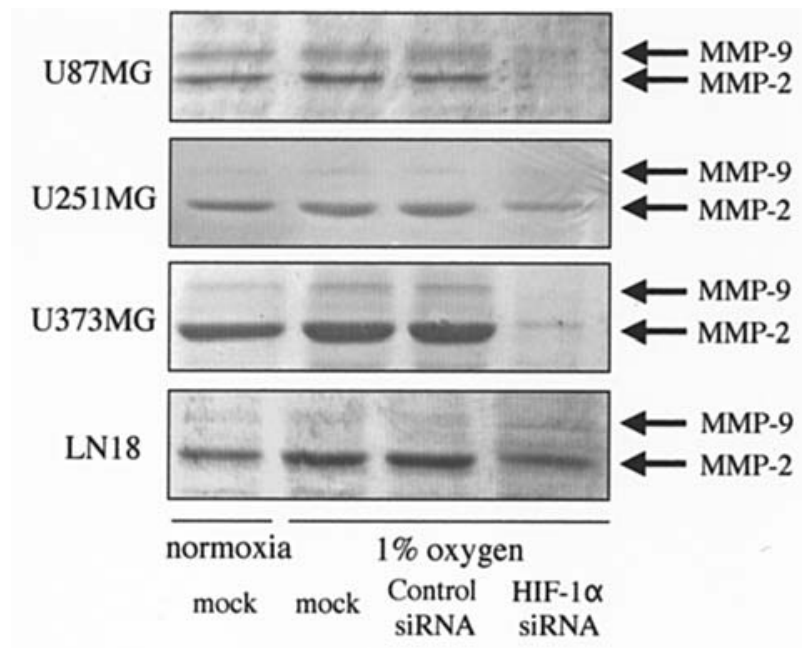

Figure 8. Enzymatic activities of MMP-2 and MMP-9 assessed by gelatin zymography. The culture supernatant from glioma cells was used for gelatin zymography. Clear lytic zones at a molecular weight of $72 \mathrm{kDa}$ demonstrate the enzyme activity of MMP-2. Both MMP-2 and MMP-9 were activated under low-oxygen conditions. The intensities of these lytic zones were clearly reduced in the conditioned medium from HIF-1 $\alpha$ siRNA-transfected cells. HIF-1 $\alpha$ siRNA decreased the enzymatic activities of MMP-2 and MMP-9 in all cell lines.

unclear and is dependent on the type of cancer and the presence or absence of genetic alterations that affect the balance between pro- and anti-apoptotic factors (26).

In the present study, we provided evidence that knockout of HIF- $1 \alpha$ expression by RNA interference led to a dramatic decrease in in vitro cell migration and invasion under hypoxia. However, tumor invasion is a complex process in which tumor cells initiate migration from the primary site of the tumor, adhere to the ECM, and degrade it with the aid of proteolytic enzymes to invade distant tissues (27). Key elements of these processes include tumor cell adhesion, migration, and proteolysis of the ECM. However, the biological functions of these elements depend on specific tissue environments and are substantially affected by the ECM of the target organ. The ECM components of the brain are different than those of other organs $(28,29)$. Therefore, in situ studies of glioma invasion require special conditions analogous to those of normal brain. We have established a novel brain slice model of glial tumor cell invasion by modifying an organotypic culture of brain tissues $(17,30)$. In the experiments using the brain slice model, we were concerned whether the normal histological structure of the slice would be maintained under hypoxic stress. To avoid this problem, brain slices incubated for 3 days under the normoxia and hypoxia were stained with hematoxylin and eosin and observed under a microscope. We confirmed that the brain slices retained their normal morphologic features $<1 \%$ oxygen for 3 days (data not shown). Introduction of HIF- $1 \alpha$ siRNA to glioma cells under hypoxic conditions inhibited the spread of the tumor cells around the tumor spheroid in the brain slice, thereby creating a welldemarcated tumor mass similar to the intitial tumor spheroid. In contrast, control siRNA-treated cells diffusely invaded the surrounding normal brain tissue in hypoxia. Collectively, these results indicated that hypoxia-induced HIF-1 $\alpha$ plays an essential role in cell motility in malignant gliomas.
MMPs are implicated in tumor cell invasion because they degrade almost all components of the ECM (31). It has been suggested that high levels of expression of MMPs are closely related to the malignant progression observed in gliomas (32). MMP-2 and MMP-9 are expressed and secreted by malignant gliomas in vivo and can modulate the invasive phenotype in vitro $(33,34)$. Therefore, we investigated whether hypoxia affected the enzyme kinetics of MMP-2 and MMP-9 in addition to TIMP-2 expression. We showed that MMP-2 mRNA and not MMP-9 mRNA, was increased under hypoxic conditions, while TIMP-2 mRNA was reduced in all glioma cell lines tested. Moreover, we found that the enzymatic activities of MMP-2 and MMP-9 were increased under the hypoxic conditions, as assessed by gelatin zymography. The hypoxia-induced activation of MMP-2 and MMP-9 was counteracted by HIF- $1 \alpha$ siRNA treatment. It has been reported that, using in situ hybridization and immunohistochemistry, MMP-2 expression is localized most prominently in tumor cells with very little signal in the vasculature, and MMP-9 is not only expressed prominently in vascular structures but also expressed in tumor cells (35). The discrepancy between mRNA levels and enzyme activity of MMP-2 and MMP-9 may be caused by the difference in their histological localization.

It should be noted that expression of HIF-1 $\alpha$ is not restricted to hypoxic cells alone in many tumors, but is also regulated by genetic alterations that activate oncogenes and inactivate suppressor genes (36-40). We have reported that PTEN gene transfer suppressed glioma cell invasion (41). In addition, we examined the relation between HIF-1 $\alpha$ expression and PTEN gene function in U87MG, which has a mutated PTEN. Transfection of the PTEN gene apparently reduced expression of HIF-1 $\alpha$ protein under hypoxic conditions (unpublished data). We believe that the context of genetic alterations shape the role of HIF-1 in the susceptibility of cells to adaptation and progression towards malignancy.

In conclusion, our results show that suppression of HIF-1 $\alpha$ inhibits the motility of human malignant glioma cells. HIF- $1 \alpha$ protein appears to be a key factor in glioma cell migration and invasion under hypoxic conditions. Although the mechanism of the effect of HIF-1 $\alpha$ on hypoxic glioma cell motility is not clear, downregulation of MMP-2 mRNA expression and inhibition of the enzymatic activities of MMP-2 and -9, along with upregulation of TIMP-2, are considered to play crucial roles in the process. These findings indicate that targeting HIF- $1 \alpha$ may be a promising therapeutic strategy against the invasion of malignant gliomas.

\section{References}

1. Semenza GL: Hypoxia, clonal selection, and the role of HIF-1 in tumor progression. Crit Rev Biochem Mol Biol 35: 71-103, 2000.

2. Wenger RH: Cellular adaptation to hypoxia: O2-sensing protein hydroxylases, hypoxia-inducible transcription factors, and O2regulated gene expression. FASEB J 16: 1151-1162, 2002.

3. Wang GL, Jiang BH, Rue EA and Semenza GL: Hypoxiainducible factor 1 is a basic-helix-loop-helix-PAS heterodimer regulated by cellular O2 tension. Proc Natl Acad Sci USA 92: 5510-5514, 1995

4. Unruh A, Ressel A, Mohamed HG, Johnson RS, Nadrowitz R, Richter E, Katschinski DM and Wenger RH: The hypoxiainducible factor-1 alpha is negative factor for tumor therapy. Oncogene 22: 3213-3220, 2003. 
5. Brown JM and Giaccia AJ: The unique physiology of solid tumors: opportunities (and problems) for cancer therapy. Cancer Res 58: 1408-1416, 1998.

6. Hockel M, Schlenger K, Hockel S and Vaupel P: Hypoxic cervical cancers with low apoptotic index are highly aggressive. Cancer Res 59: 4525-4528, 1999.

7. Vaupel P, Thews $\mathrm{O}$ and Hoeckel M: Treatment resistance of solid tumors: role of hypoxia and anemia. Med Oncol 18: 243-259, 2001.

8. Sondergaad KL, Hilton DA, Penney M, Ollerenshaw M and Demaine AG: Expression of hypoxia-inducible factor 1 alpha in tumours of patients with glioblastoma. Neuropathol Appl Neurobiol 28: 210-217, 2002 .

9. Zagzag D, Zhong H, Scalzitti JM, Laughner E, Simons JW and Semenza GL: Expression of hypoxia-inducible factor 1alpha in brain tumors: association with angiogenesis, invasion, and progression. Cancer 88: 2606-2618, 2000.

10. Mosmann T: Rapid colorimetric assay for cellular growth and survival: Application to proliferation and cytotoxicity assays. J Immunol Methods 65: 55-63, 1983.

11. Ohnishi T, Arita N and Hayakawa T: Motility factor produced by malignant glioma cells: role in tumor invasion. J Neurosurg 73: 881-888, 1990

12. Ohnishi T, Arita N and Hiraga S: Fibronectin-mediated cell migration promotes glioma cell invasion through chemokinetic activity. Clin Exp Metastasis 15: 538-546, 1997.

13. Albini A, Iwamoto Y, Kleinman HK, Martin GR, Aaronson SA and Kozlowski JM: A rapid in vitro assay for quantitating the invasive potential of tumor cells. Cancer Res 47: 3239-3245, 1987.

14. Amer AP, De Armond SJ, Spencer DR, Coopersmith PF, Ramos DM and Rosenblum ML: Development of an in vitro extracellular matrix assay for studies of brain tumor cell invasion. J Neurooncol 20: 1-15, 1994.

15. Ohnishi T, Arita N, Hayakawa T, Kawahara K, Kato K and Kakinuma A: Purification of motility factor (GMF) from human malignant glioma cells and its biological significance in tumor invasion. Biochem Biophys Res Commun 193: 518-525, 1993.

16. Schor SL, Schor AM and Winn B: The use of three-dimensional collagen gels for the study of tumor cell invasion in vitro: experimental parameters influencing cell migration into the gel matrix. Int J Cancer 29: 57-62, 1982.

17. Ohnishi T, Matsumura H, Izumoto S, Hiraga S and Hayakawa T: A novel model of glioma cell invasion using organotypic brain slice culture. Cancer Res 58: 2935-2940, 1998.

18. Stoppini L, Buchs PA and Muller D: A simple method for organotypic cultures of nervous tissue. J Neurosci Methods 37: 173-182, 1991.

19. Murakami M, Goto S, Yoshikawa M, Goto T, Hamasaki T, Rutka JT, Kuratsu J and Ushio Y: The invasive features of glial and non-central nervous system tumor cells are different on organotypic brain slices from newborn rats. Int J Oncol 18: 721-727, 2001.

20. Horan PK, Melnicoff MJ, Jensen BD and Slezak SE: Fluorescent cell labeling for in vivo and in vitro cell tracking. Methods Cell Biol 33: 469-490, 1990.

21. Chomczynski P and Sacchi N: Single step method of RNA isolation by acidic guanidinium thiocyanate ohenol-chloroform extraction. Anal Biochem 162: 156-159, 1987.

22. Davies B, Miles DW and Happerfield LC: Activity of type I collagenases in benign and malignant breast disease. Br J Cancer 67: 1126-1131, 1993.

23. Nagato S, Nakagawa K, Harada H, Kohno S, Fujiwara H, Sekiguchi K, Ohue S, Iwata S and Ohnishi T: Downregulation of laminin alpha4 chain expression inhibits glioma invasion in vitro and in vivo. Int J Cancer 117: 41-50, 2005.

24. Hockel $\mathrm{M}$ and Vaupel P: Tumor hypoxia definitions and current clinical, biologic, and molecular aspects. J Natl Cancer Inst 93: 266-276, 2001.
25. Gregg LS: Targeting HIF-1 for cancer therapy. Nat Rev Cancer 3: 721-732, 2003.

26. Zhou J, Schmid T, Schnitzer S and Brune B: Tumor hypoxia and cancer progression. Cancer Lett 237: 10-21, 2006.

27. Liotta LA, Rao CN and Wewer UM: Biochemical interactions of tumor cells with the basement membrane. Ann Rev Biochem 55: 1037-1057, 1986.

28. Paetau A, Mellstom K, Vaheri A and Haltia M: Distribution of a major connective tissue protein, fibronectin, in normal and neoplastic human nervous tissue. Acta Neuropathol 51: 47-51, 1980.

29. Rutka JT, Apodaca G, Stern R and Rosenblum M: The extracellular matrix of the central and peripheral nervous systems: structures and function. J Neurosurg 69: 155-170, 1988.

30. Matsumura H, Ohnishi T, Kanemura Y, Maruno M and Yoshimine T: Qunatitative analysis of glioma cell invasion by confocal laser scanning microscopy in a novel brain slice model. Biochem Biophys Res Commun 269: 513-520, 2000.

31. Sato H, Takino T, Okada Y, Cao J, Shinagawa A, Yamamoto E and Seiki M: A matrix metalloproteinase expressed on the surface of invasive tumour cells. Nature 370: 61-65, 1994.

32. Nakano A, Tani K, Miyazaki Y, Yamamoto J and Furuyama I: Matrix metalloproteinases and tissue inhibitors of metalloproteinases in human gliomas. J Neurosurg 83: 298-307, 1995.

33. VanMeter TE, Rooprai HK, Kibble MM, Fillmore HL, Broaddus WC and Pilkington GJ: The role of matrix metalloproteinase gene in glioma invasion: co-dependent and interactive proteolysis. J Neurooncol 53: 213-235, 2001.

34. Yamamoto M, Mohanam S, Sawaya R, Fuller GN, Seiki M, Sato H, Gokaslan ZL, Liotta LA, Nicolson GL and Rao JS: Differential expression of membrane-type matrix metalloproteinase and its correlation with gelatinase A activation in human malignant brain tumors in vivo and in vitro. Cancer Res 56: 384-392, 1996.

35. Raithatha SA, Muzik H, Muzik H, Rewcastle NB, Johnston RN, Edwards DR and Forsyth PA: Localization of gelatinase-A and gelatinase-B mRNA and protein in human gliomas. Neurooncol 2: $145-150,2000$.

36. Jiang BH, Agani F, Passaniti A and Semenza GL: V-SRC induces expression of hypoxia-inducible factor 1 (HIF-1) and transcription of genes encoding vascular endothelial growth factor and enolase 1: involvement of HIF-1 in tumor progression. Cancer Res 57: 5328-5335, 1997.

37. Laughner E, Taghavi P, Chiles K, Mahon PC and Semenza GL: HER2 (neu) signaling increases the rate of hypoxia-inducible factor 1alpha (HIF-1alpha) synthesis: novel mechanism for HIF-1mediated vascular endothelial growth factor expression. Mol Cell Biol 21: 3995-4004, 2001.

38. Maxwell PH, Wiesener MS, Chang GW, Clifford SC, Vaux EC, Cockman ME, Wykoff CC, Pugh CW, Maher ER and Ratcliffe PJ: The tumour suppressor protein VHL targets hypoxia-inducible factors for oxygen-dependent proteolysis. Nature 399: 271-275, 1999.

39. Zhong H, Chiles K, Feldser D, Laughner E, Hanrahan C, Georgescu MM, Simons JW and Semenza GL: Modulation of hypoxia-inducible factor 1alpha expression by the epidermal growth factor/phosphatidylinositol 3-kinase/PTEN/AKT/FRAP pathway in human prostate cancer cells: implications for tumor angiogenesis and therapeutics. Cancer Res 60: 1541-1545, 2000 .

40. Zundel W, Schindler C, Haas-Kogan D, Koong A, Kaper F, Chen E, Gottschalk AR, Ryan HE, Johnson RS, Jefferson AB, Stokoe D and Giaccia AJ: Loss of PTEN facilitates HIF-1mediated gene expression. Genes Dev 14: 391-396, 2000.

41. Furukawa K, Kumon Y, Harada H, Kohno S, Nagato S, Teraoka M, Fujiwara S, Nakagawa K, Hamada K and Ohnishi T: PTEN gene transfer suppresses the invasive potential of human malignant gliomas by regulating cell invasion-related molecules. Int J Oncol 29: 73-81, 2006. 